\title{
THE EFFECT OF PRO-ECOLOGICAL PROCEDURES AND INSECT FORAGING ON THE TOTAL CONTENT OF PHENOL COMPOUNDS IN WINTER WHEAT
}

\author{
Robert Lamparski, ${ }^{1 *}$ Maciej BalcereK, ${ }^{2}$ Daniel Modnicki, ${ }^{2}$ \\ KAROL KOTWICA $^{3}$ and Maria WAWRZYNIAK ${ }^{1}$ \\ ${ }^{1}$ Department of Entomology and Molecular Phytopathology, University of Technology and \\ Life Sciences, 20 Kordeckiego St., 85-225 Bydgoszcz, Poland \\ ${ }^{2}$ Chair of Pharmacognosy, Nicolaus Copernicus University, Collegium Medicum, \\ M. Skłodowskiej-Curie 9, 85-094 Bydgoszcz, Poland \\ ${ }^{3}$ Department of Plant Growth Principles and Experimental Methodology, University of Technology and \\ Life Sciences, 20 Kordeckiego St., 85-225 Bydgoszcz, Poland
}

(Received: April 22, 2014; accepted: October 31, 2014)

\begin{abstract}
In laboratory conditions, the effect of pro-ecological procedures (application of effective microorganisms and Asahi SL biostimulator) and foraging by insects [cereal leaf beetle (Oulema melanopa L.) and bird cherry-oat aphid (Rhopalosiphum padi (L.)] on the total content of phenolic compounds in winter wheat, was studied. Correlations between the total content of phenolic compounds (determined by the FolinCiocalteau colorimetric method) expressed as the amount of pyrogallol in wheat plants: undamaged, damaged by $O$. melanopa, damaged by $R$. padi, the length of feeding scar left by cereal leaf beetle and the number of pricks made by actively feeding insects of bird cherry-oat aphid were analysed. The wheat was treated by EM inoculant and a biostimulator. The mode of application of the preparations used had a significant effect on level the total phenolic compounds in the undamaged wheat and the wheat exposed to foraging by the above-mentioned insects. The plants not exposed to insects foraging contained greater amounts of phenolic compounds than those exposed to the insects. The correlation between the total content of phenols in the wheat damaged by the insects in the 'no-choice' conditions, proved insignificant.
\end{abstract}

Keywords: Content of total phenolic compounds - wheat - Oulema melanopa L. - Rhopalosiphum padi (L.) - effective microorganism - Asahi SL biostimulant

\section{INTRODUCTION}

For at least 100 million years, the plants have developed many strategies of natural resistance to insects $[23,26]$. Comprehensive identification of these mechanisms permits their future use for plant protection [7].

The choice of host plants by insects, especially aphids, is a complex process, which depends on many factors. A particularly important role is played by allelochemicals which can affect the behaviour and/or insects physiology [21]. One of the most active groups of allelochemicals are phenolic compounds, classified as secondary metabolites. They contribute to environmental interactions and actively affect growth and development of insects $[3,5,13,15]$.

\footnotetext{
*Corresponding author; e-mail: robert@utp.edu.pl
} 
The pro-ecological policy adopted in Poland has prompted us to search for other than industrial yield-protecting and yield-enhancing agents, promoting the increase in biodiversity of agrocenoses and plant resistance $[8,9]$. Such agents include inoculation with effective microorganisms (EM) and Asahi SL biostimulant. They maintain or improve the physiochemical soil properties, increase the biodiversity and activity of soil microorganisms, limit the populations of phytophagous entomofauna, neutralise toxic compounds, enhance resistance of the plants to stress conditions $[10,16,18]$. A few authors have demonstrated unfavourable effect of biostimulants on the occurrence of pests, e.g. red spider mite (Tetranychus urticae) on the plants of cucumber (Cucumis sativus) [24], or cereal crops pests in field conditions [10, 11].

The present state of knowledge on the effect of pro-ecological methods of soil fertilisation and enhancement of the plant resistance to pests feeding is insufficient. So far no studies have been performed to illustrate the effect of use of biopreparations on cereal crops on the foraging of insects and on the secretion of secondary metabolism products.

The aim of this study was to check the effect of EM inoculant and Asahi SL biostimulant application in various straw management conditions on the general content of phenolic compounds produced by winter wheat plants and on the extent of pest foraging on these species.

\section{MATERIALS AND METHODS}

\section{Plant material}

The laboratory tests were performed as part of our own research project PB-7295/B/ P01/2011/40 (total input: PLN 133 900), over 2012 and 2013 in the laboratory of the Department of Entomology and Molecular Phytopathology of the University of Technology and Life Sciences in Bydgoszcz, Poland and the Department of Pharmacognosy of the Nicolaus Copernicus University in Torun, Poland.

The plants of winter wheat, Arktis cultivar, were sown into pots $(\varnothing=13 \mathrm{~cm}, 10$ $\mathrm{cm}$ high) filled with a very good rye complex soil obtained from study plots from the field experiment of the project. At the depth of $2.5-3.0 \mathrm{~cm}, 10$ caryopses were sown in each pot. The sowing started in the $3^{\text {rd }}$ decade of March and it was continued in a few series until mid-April.

The inoculant and biostimulator were applied as specified below:

EM inoculant introduced into the soil after harvest (in the autumn) in the amount of $5.0 \mathrm{dm}^{3} \mathrm{EM}^{-1} \cdot \mathrm{ha}^{-1}$, as recommended by the producer,

EM inoculant applied on the leaves in the amount of $2.5 \mathrm{dm}^{3} \mathrm{EM}^{-1} \cdot \mathrm{ha}^{-1}(0.7 \mathrm{ml} \mathrm{EM}$

$+10 \mathrm{ml} \mathrm{H}{ }_{2} \mathrm{O}$ per 100 plants) in phase $\mathrm{BBCH} 21$,

Asahi SL* biostimulator applied once on the leaves in the amount of $1.0 \mathrm{dm}^{3} \cdot \mathrm{ha}^{-1}$

$\left(0.028 \mathrm{ml}+10 \mathrm{ml} \mathrm{H}_{2} \mathrm{O}\right.$ per 100 plants) in phase $\mathrm{BBCH} 21$; (in the case of com-

\footnotetext{
* The biostimulant of plant resistance (biologically active substance: sodium para-nitrophenolate $0.3 \%$ and sodium ortho-nitrophenolate $-0.2 \%$ and sodium 5-nitroguaiacolate $-0.1 \%$ ).
} 
bined use $2 \times \mathrm{EM}+1 \times \mathrm{BA}$, the biostimulator was applied in 2 days after application of EM inoculant on the leaves),

Asahi SL biostimulator applied twice on the leaves, $2 \times 0.5 \mathrm{dm}^{3} \cdot \mathrm{ha}^{-1}(2 \times 0.014 \mathrm{ml}+$ $10 \mathrm{ml} \mathrm{H}_{2} \mathrm{O}$ per 100 plants) in phase $\mathrm{BBCH} 21$ and $\mathrm{BBCH} 28$; (in the case of combined use $2 \times \mathrm{EM}+2 \times \mathrm{BA}$ the first dose of the biostimulator was applied in 2 days after EM inoculant application on the leaves).

The plants during growth were supplied with mineral fertilisers in the amounts corresponding to the doses of: $140 \mathrm{~kg} \mathrm{~N} \cdot \mathrm{ha}^{-1}, 30 \mathrm{~kg} \mathrm{P}_{2} \mathrm{O}_{5} \cdot \mathrm{ha}^{-1}$ and $60 \mathrm{~kg} \mathrm{~K}_{2} \mathrm{O} \cdot \mathrm{ha}^{-1}$ as well as watered once a week, with the amount of about $100 \mathrm{ml}$ per pot. The plants were grown in an air-conditioned room, at $21 \pm 1{ }^{\circ} \mathrm{C}$, L16:D8 photoperiod, and $70 \% \mathrm{RH}$.

\section{Entomological experiments}

About 7 weeks after sowing the plants reached the phase $\mathrm{BBCH}-32$ and were ready for specific laboratory tests.

\section{Assay of the total content of phenolic compounds}

The end section of the top leaf of each wheat plant growing in laboratory conditions and a single pair of imagines of cereal leaf beetle (O. melanopa) (sex differentiation - in copula) or 5 individuals of bird cherry-oat aphid (R. padi) (mature larvae or imagines) were placed on a Petri dish $(\varnothing 10 \mathrm{~cm})$. After 2 days the insects were removed, the whole plants were cut off with scissors at the soil surface, weighed and for 2 successive days they were dried at the temperature of $32{ }^{\circ} \mathrm{C}$. Dried, weighed and ground plants were exposed to specific determination at the Department of Pharmacognosy, the Nicolaus Copernicus University, Torun, Poland in 3 reps.

\section{No choice test on insect feeding}

Cereal leaf beetles. The lengths of feeding scar [4] caused by 1 pair of imago (sex differentiation - in copula), for 3 days of feeding were compared. The results are presented as the mean length of damage on a $5 \mathrm{~cm}$ long leaf consumed by the imago of cereal leaf beetle [mm].

Aphids. The number of pricks made by actively feeding insects, i.e. those actually penetrating the plant tissues, was counted. The penetration started in 4-5 minutes after examination of the plant surface by the insects $[12,22]$. The observations were made 5 times a week at about every 2-3 hours during 3 days of feeding of two insects. The so-called maximum number of actively feeding insects was calculated as the product of the number of insects, days of observation and the number of observations 
per day, namely adequately 3 days $\times 2$ insects $\times 5$ observations [30]. The results are presented as a ratio of the actually identified number of insects actively feeding as compared to their maximum number [expressed in \%].

The insects were brought from fields and placed on wheat plants in insulators $(55 \times 35 \times 70 \mathrm{~cm})$. The insulators with plants were kept under controlled conditions of the laboratory of the Department of Entomology and Molecular Phytopathology. The study involved the use of imagines of cereal leaf beetle and wingless or winged bird cherry-oat aphid.

\section{Phenolic compounds}

Total contents of phenolic compounds in the plants extracts were determined by the Folin-Ciocalteau colorimetric method described in Pharmacopoeia Polonica IX [19].

All determinations were performed in triplicate. Total content of phenolic compounds (\%) was expressed as pyrogallol (PG) equivalents. Results were expressed as the mean \pm standard deviation (SD). Total content of phenolic compounds was expressed as equivalent to $\mathrm{g} P G \cdot \mathrm{g}^{-1}$ dry weight of plant material.

Table 1

Effect of the application of (I) the doses of effective microorganisms (EM), (II) biostimulant Asahi (BA) as well as (III) the method of treatment of forecrop straw on the total content of phenolic compounds converted into pyrogallol in the wheat plants undamaged by insects [\% DM]

\begin{tabular}{|c|c|c|c|c|c|}
\hline \multirow{2}{*}{ I } & \multirow{2}{*}{ III } & \multicolumn{3}{|c|}{ II } & \multirow{2}{*}{ Mean } \\
\hline & & $1 \times \mathrm{BA}$ & $2 \times \mathrm{BA}$ & $0 \times \mathrm{BA}$ & \\
\hline $1 \times$ EM & $\mathrm{CS}$ & $1.346 \pm 0.138$ & $1.058 \pm 0.027$ & $1.037 \pm 0.048$ & $1.147 \pm 0.167$ \\
\hline $1 \times \mathrm{EM}$ & RS & $1.609 \pm 0.019$ & $1.523 \pm 0.045$ & $1.500 \pm 0.036$ & $1.544 \pm 0.058$ \\
\hline \multicolumn{2}{|l|}{ Mean } & $1.478 \pm 0.169$ & $1.290 \pm 0.257$ & $1.269 \pm 0.257$ & $1.346 \pm 0.238^{\mathrm{b}}$ \\
\hline $2 \times \mathrm{EM}$ & CS & $1.862 \pm 0.102$ & $1.430 \pm 0.141$ & $1.694 \pm 0.121$ & $1.662 \pm 0.216$ \\
\hline $2 \times \mathrm{EM}$ & RS & $1.447 \pm 0.060$ & $1.202 \pm 0.034$ & $1.410 \pm 0.056$ & $1.353 \pm 0.123$ \\
\hline \multicolumn{2}{|l|}{ Mean } & $1.655 \pm 0.240$ & $1.316 \pm 0.155$ & $1.552 \pm 0.177$ & $1.507 \pm 0.233^{\mathrm{a}}$ \\
\hline $0 \times \mathrm{EM}$ & $\mathrm{CS}$ & $0.960 \pm 0.032$ & $0.536 \pm 0.015$ & $0.538 \pm 0.006$ & $0.678 \pm 0.212$ \\
\hline $0 \times \mathrm{EM}$ & RS & $1.655 \pm 0.012$ & $0.429 \pm 0.016$ & $0.550 \pm 0.017$ & $0.878 \pm 0.585$ \\
\hline \multicolumn{2}{|l|}{ Mean } & $1.307 \pm 0.381$ & $0.482 \pm 0.060$ & $0.544 \pm 0.013$ & $0.778 \pm 0.439^{c}$ \\
\hline \multicolumn{2}{|c|}{$\mathrm{CS}$} & $1.389 \pm 0.402$ & $1.008 \pm 0.396$ & $1.089 \pm 0.501$ & $1.162 \pm 0.452^{b}$ \\
\hline \multicolumn{2}{|c|}{$\mathrm{RS}$} & $1.570 \pm 0.100$ & $1.051 \pm 0.488$ & $1.153 \pm 0.456$ & $1.258 \pm 0.439^{a}$ \\
\hline \multicolumn{2}{|l|}{ Mean } & $1.480 \pm 0.299^{\mathrm{a}}$ & $1.030 \pm 0.431^{\mathrm{c}}$ & $1.121 \pm 0.468^{b}$ & $1.210 \pm 0.444$ \\
\hline
\end{tabular}

Data are presented as mean $\pm \mathrm{SD}, \mathrm{CS}$ - crushed straw, RS - removed straw.

$\mathrm{a}, \mathrm{b}, \mathrm{c}=$ Object means indicated by the superscripts (for factors I, II, III) are significatly different at $\alpha=0.05$ according to Tukey's test. 


\section{Statistical analyses}

The results were subjected to the analysis of variance (ANOVA) in a completely randomised design applying Statistica 2013 software, and the significance of differences between object means was evaluated with the Tukey test. The correlations between the amount of phenols contained in the plants damaged by aphids or cereal leaf beetle and the size of damage caused by those insects were determined using the analysis of linear correlation.

\section{RESULTS}

The mode of EM inoculation and Asahi biostimulant application had a significant effect on the secretion of the total content of phenolic compounds as converted into pyrogallol in the plants undamaged and exposed to the foraging by cereal leaf beetle or bird cherry-oat aphid. The plants with no insect foraging produced a higher total content of phenolic compounds than the plants damaged by cereal leaf beetle or aphids; by 0.450 and 0.383 pp DM, respectively (Tables 1 and 2).

Table 2

Effect of the application of (I) the doses of effective microorganisms (EM), (II) of biostimulant Asahi (BA) as well as (III) the method of treatment of forecrop straw on the total content of phenolic compounds converted into pyrogallol in the wheat plants damaged by cereal leaf beetle (O. melanopa) [\%]

\begin{tabular}{|c|c|c|c|c|c|}
\hline \multirow{2}{*}{ I } & \multirow{2}{*}{ III } & \multicolumn{3}{|c|}{ II } & \multirow{2}{*}{ Mean } \\
\hline & & $1 \times \mathrm{BA}$ & $2 \times \mathrm{BA}$ & $0 \times \mathrm{BA}$ & \\
\hline $1 \times \mathrm{EM}$ & $\mathrm{CS}$ & $0.221 \pm 0.015$ & $0.237 \pm 0.020$ & $0.246 \pm 0.012$ & $0.235 \pm 0.018$ \\
\hline $1 \times \mathrm{EM}$ & RS & $0.152 \pm 0.026$ & $0.182 \pm 0.008$ & $1.110 \pm 0.047$ & $0.481 \pm 0.473$ \\
\hline \multicolumn{2}{|l|}{ Mean } & $0.186 \pm 0.042$ & $0.209 \pm 0.033$ & $0.678 \pm 0.474$ & $0.358 \pm 0.348^{c}$ \\
\hline $2 \times \mathrm{EM}$ & $\mathrm{CS}$ & $1.530 \pm 0.031$ & $1.533 \pm 0.053$ & $1.878 \pm 0.039$ & $1.647 \pm 0.177$ \\
\hline $2 \times \mathrm{EM}$ & RS & $1.509 \pm 0.025$ & $0.948 \pm 0.012$ & $1.245 \pm 0.021$ & $1.234 \pm 0.244$ \\
\hline \multicolumn{2}{|l|}{ Mean } & $1.519 \pm 0.027$ & $1.241 \pm 0.322$ & $1.562 \pm 0.348$ & $1.441 \pm 0.296^{\mathrm{a}}$ \\
\hline $0 \times \mathrm{EM}$ & $\mathrm{CS}$ & $0.234 \pm 0.045$ & $0.416 \pm 0.004$ & $0.522 \pm 0.020$ & $0.391 \pm 0.129$ \\
\hline $0 \times \mathrm{EM}$ & RS & $0.930 \pm 0.017$ & $0.356 \pm 0.008$ & $0.435 \pm 0.006$ & $0.573 \pm 0.270$ \\
\hline \multicolumn{2}{|l|}{ Mean } & $0.582 \pm 0.382$ & $0.386 \pm 0.034$ & $0.478 \pm 0.050$ & $0.482 \pm 0.225^{b}$ \\
\hline \multicolumn{2}{|c|}{$\mathrm{CS}$} & $0.661 \pm 0.652$ & $0.729 \pm 0.609$ & $0.882 \pm 0.773$ & $0.757 \pm 0.656$ \\
\hline \multicolumn{2}{|c|}{ RS } & $0.864 \pm 0.590$ & $0.495 \pm 0.348$ & $0.930 \pm 0.377$ & $0.763 \pm 0.476$ \\
\hline \multicolumn{2}{|l|}{ Mean } & $0.762 \pm 0.612^{b}$ & $0.612 \pm 0.496^{c}$ & $0.906 \pm 0.581^{\mathrm{a}}$ & $0.760 \pm 0.567$ \\
\hline
\end{tabular}

Data are presented as mean $\pm \mathrm{SD}, \mathrm{CS}$ - crushed straw, RS - removed straw, n.s. - no significance. $\mathrm{a}, \mathrm{b}, \mathrm{c}=$ Object means indicated by the superscripts (for factors I, II, III) are significatly different at $\alpha=0.05$ according to Tukey's test. 
Table 3

Effect of the application of (I) doses of effective microorganisms (EM),

(II) biostimulant Asahi (BA) as well as (III) the method of treatment of forecrop straw on the number of pricks made by actively feeding insects of bird cherry-oat aphid (R. padi) on wheat leaves [\%]

\begin{tabular}{|c|c|c|c|c|c|}
\hline \multirow{2}{*}{ I } & \multirow{2}{*}{ III } & \multicolumn{3}{|c|}{ II } & \multirow{2}{*}{ Mean } \\
\hline & & $1 \times \mathrm{BA}$ & $2 \times \mathrm{BA}$ & $0 \times \mathrm{BA}$ & \\
\hline $1 \times \mathrm{EM}$ & $\mathrm{CS}$ & $62.0 \pm 1.83$ & $58.0 \pm 1.83$ & $59.3 \pm 1.49$ & $59.8 \pm 2.32$ \\
\hline $1 \times \mathrm{EM}$ & RS & $62.6 \pm 1.49$ & $59.3 \pm 1.49$ & $60.0 \pm 2.36$ & $60.7 \pm 2.23$ \\
\hline \multicolumn{2}{|l|}{ Mean } & $62.3 \pm 1.59$ & $58.7 \pm 1.70$ & $59.7 \pm 1.87$ & $60.2 \pm 2.28^{a}$ \\
\hline $2 \times \mathrm{EM}$ & $\mathrm{CS}$ & $60.7 \pm 2.79$ & $62.7 \pm 5.48$ & $64.0 \pm 2.79$ & $62.5 \pm 3.88$ \\
\hline $2 \times \mathrm{EM}$ & RS & $61.3 \pm 2.98$ & $62.0 \pm 5.06$ & $64.7 \pm 1.83$ & $62.7 \pm 3.60$ \\
\hline \multicolumn{2}{|l|}{ Mean } & $61.0 \pm 2.72$ & $62.4 \pm 4.98$ & $64.3 \pm 2.27$ & $62.6 \pm 3.68^{b}$ \\
\hline $0 \times \mathrm{EM}$ & $\mathrm{CS}$ & $61.3 \pm 3.80$ & $62.7 \pm 4.35$ & $63.3 \pm 2.36$ & $62.4 \pm 3.44$ \\
\hline $0 \times \mathrm{EM}$ & RS & $60.7 \pm 2.79$ & $61.3 \pm 1.83$ & $64.0 \pm 4.35$ & $62.0 \pm 3.28$ \\
\hline \multicolumn{2}{|l|}{ Mean } & $61.0 \pm 3.15$ & $62.0 \pm 3.22$ & $63.7 \pm 3.32$ & $62.2 \pm 3.31^{b}$ \\
\hline \multicolumn{2}{|c|}{$\mathrm{CS}$} & $61.3 \pm 2.75$ & $61.1 \pm 4.48$ & $62.2 \pm 3.00$ & $61.6 \pm 3.45$ \\
\hline \multicolumn{2}{|c|}{$\mathrm{RS}$} & $61.5 \pm 2.45$ & $60.9 \pm 3.20$ & $62.9 \pm 3.54$ & $61.8 \pm 3.14$ \\
\hline \multicolumn{2}{|l|}{ Mean } & $61.4 \pm 2.56$ & $61.0 \pm 3.83$ & $62.6 \pm 3.24$ & $61.7 \pm 3.28$ \\
\hline
\end{tabular}

Data are presented as mean $\pm \mathrm{SD}, \mathrm{CS}$ - crushed straw, RS - removed straw, n.s. - no significance. $\mathrm{a}, \mathrm{b}=$ Object means indicated by the superscripts (for factors I, II, III) are significatly different at $\alpha=0.05$ according to Tukey's test.

The highest level of the total content of phenolic compounds was found in the wheat plants subjected to twice repeated application of EM inoculation $(2 \times \mathrm{EM})$ (Tables 1 and 2). The dose of Asahi biostimulant applied once $(1 \times \mathrm{BA})$ resulted in the highest concentration of the total content of phenolic compounds only in the wheat plants unexposed to pests (1.480\% DM) (Table 1$)$.

Incorporation of straw with soil significantly decreased (by $0.096 \mathrm{pp} \mathrm{DM}$ ) the total content of phenolic compounds in wheat undamaged by insects, as compared with the plants growing in the soil without straw (Table 1). Introduction of straw into soil did not change significantly the contents of phenols secreted in the plants damaged by the insects tested (Table 2).

The mean feeding scar length of wheat leaf injury by imagines of cereal leaf beetle was longer than $205 \mathrm{~mm}$. No correlation was found between the factors analysed and the size of damage caused by this insect.

The number of actively feeding insects of bird cherry-oat aphid was different, corresponding to the mode of EM inoculation (Table 3). The lowest number of insects during active feeding was determined on the plants in the study plots where inoculation was applied once $(1 \times \mathrm{EM})$. The effect of the mode of EM inoculation on the number of actively feeding insects of aphid was found to depend on the mode of 
Table 4

Correlations studied between the total content of phenolic compounds expressed in the amount of pyrogallol in wheat plants: undamaged (UPlant), damaged by O. melanopa (OmPlant), damaged by $R$. padi (RpPlant), the feeding scar length left by cereal leaf beetle (OmDamage) and the number of pricks made by actively feeding insects of bird cherry-oat aphid (RpDamage)

\begin{tabular}{|c|c|c|c|c|c|c|}
\hline & & UPlant & RpPlant & OmPlant & RpDamage & OmDamage \\
\hline \multirow{5}{*}{ 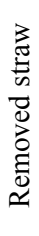 } & UPlant & 1.00 & & & & \\
\hline & RpPlant & -0.178 & 1.00 & & & \\
\hline & OmPlant & 0.308 & 0.703 & 1.000 & & \\
\hline & $R p$ Damage & -0.323 & 0.471 & 0.091 & 1.000 & \\
\hline & OmDamage & -0.206 & 0.397 & 0.323 & 0.163 & 1.00 \\
\hline \multirow{5}{*}{ 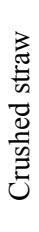 } & UPlant & 1.00 & & & & \\
\hline & RpPlant & 0.653 & 1.00 & & & \\
\hline & OmPlant & 0.722 & 0.722 & 1.000 & & \\
\hline & RpDamage & -0.006 & 0.170 & 0.473 & 1.000 & \\
\hline & OmDamage & 0.105 & -0.090 & 0.326 & 0.009 & 1.00 \\
\hline
\end{tabular}

The wheat plants were treated with EM and biostimulant in various straw management conditions. Matrix of linear correlation coefficients $r$-Pearson $(p=0.05)$.

biostimulant application. A single application of EM inoculation into the soil statistically significantly decreased the number of actively feeding insects with respect to that on the plants from the plots in which the biostimulant was applied twice during the wheat vegetation.

The correlations between the size of damage caused by aphids or cereal leaf beetle and the amount of phenols contained in the dry weight of wheat plants affected by the application of the inoculation of effective microorganisms (EM) as well as biostimulant were, in general, positive but weak and statistically insignificant (Table 4). The lack of straw or its incorporation within the soil did not change the strength of the correlation when considering aphid foraging. The lack of straw in the soil, however, intensified the correlation between the content of phenols in the dry weight of plants and the intensity of cereal leaf beetle feeding $(r=0.471)$, as compared with that in the plants from the study plots in which crushed straw was incorporated with the soil $(\mathrm{r}=0.170)$.

\section{DISCUSSION}

Cereal leaf beetle (O. melanopa) and bird cherry-oat aphid (R. padi) represent the most burdensome pests of cereal crops in Poland as well as in the world. They cause characteristic injuries on leaves [4] or induce less or more visible chloritic changes in the host plant leaf surface [20]. A number of methods have been proposed for their control. To minimise the effect of insecticides harmful for the natural environment, 
other methods for limiting the abundance of these insects have been searched for. With regard to this, it is important to get acquaintance with the chemical interactions between the plants and pests, which includes the secretion of secondary metabolites as well as the adaptation of herbivores to them [26].

The total content of polyphenols was established by applying the Folin-Ciocalteu method which, according to Leszczyński [12], permits determination of the content of all the phenolic compounds occurring in the extract.

Results of this study demonstrated that the wheat plants, which were not exposed to the effect of pests, produced higher amounts of phenolic compounds than the plants damaged by cereal leaf beetle or aphids, which is in agreement with the results reported by Wójcicka et al. [27] and Wójcicka [25] on triticale plants. Similarly, foraging by $S$. avenae decreased the level of phenols in cereals: maize and barley [6], which could be due to the time and the order of triggering of the defence reactions. Maffei et al. [14] claim that the metabolic changes appear after a few hours to a few days from the start of feeding. However, in this study the plants must have had too little time to produce a greater amount of phenolic compounds.

The wheat analysed in the present work contain 1.210 (plants undamaged by insects), 0.760 (plants damaged by cereal leaf beetle) and 0.827 (plants damaged by bird cherry-oat aphids) \% DM of phenolic compounds depending on whether it was exposed to the damage of insects or not. Both plants representing the family of grasses and others contain considerable amounts of phenolic compounds. Atanassova et al. [1] have assayed the content of polyphenols (with the Folin-Ciocalteu method) in a few known medicinal plants. They have found that lemon balm (Melissa officinalis) contains 48.86 of total phenolic, Sage (Salvia officinalis) - 27.94 and peppermint (Mentha piperita) - 45.25 (gallic acid eq per $100 \mathrm{~g} \mathrm{DM}$ ). Modnicki and Balcerek [17] have demonstrated that sweet basil (Ocimum basillicum) contains from 2.24 to 2.81, oregano (Origanum vulgare) from 2.75 to 4.85 and common thyme (Thymus vulgaris) - from 3.37 to $3.56 \%$ DW in PG eq.

A method, similar to that applied in the present study, for assaying of the total content of phenolic compounds was used in the study on the grasses: Australian bluestem (Bothriochloa bladhii), Chinese silver grass (Miscanthus sinensis) as well as common reed (Phragmites australis). The results show that the highest amount of polyphenolic compounds was found in the aboveground parts of B. bladhii $(1.41 \%)$, and a lower value was recorded for $M$. sinensis $(1.17 \%)$. The lowest values were noted for the extract from common reed (P. australis) $-0.81 \%$ as converted into pyrogallol [2].

A pair of imagines of cereal leaf beetle consumed an average of more than $205 \mathrm{~mm}$ of leaf tissue in 3 days of feeding. Clement et al. [4] have analysed the feeding scar length left on wild grass Phleum alpinum as a result of feeding of three males and 3 females of $O$. menalopa for 24 hours of the experiment. The authors have reported that on the grasses infested by a fungus representing the genus Neothypodium $97.3 \pm 40.5 \mathrm{~mm}(\mathrm{E}+)$ scar length, meanwhile on those free from this fungus $74.5 \pm 19.7$ $\mathrm{mm}(\mathrm{E}-)$ of the trace length could be recorded. 
In the present study no correlation was found between the intensity of insects foraging under 'no choice' conditions and the amount of phenolic compounds produced by the wheat plants. In contrast, Eleftherianos et al. [6] have reported an opposite correlation between the total concentration of phenols in maize and barley and the fecundity of aphids (cereal leaf beetle and bird cherry-oat aphids) at various cereal development stages.

The application of the pro-ecological preparations during plant growth did not result in any significant differences in the insect foraging (under 'no choice' conditions) as compared with the control. The insects had no possibility to choose the food and the changes in the amount of phenols produced as well as the application of the preparations did not form any barrier for them, which would effectively limit the foraging. In field experiments when insects during their flight in search for food have a possibility to choose - evaluate or/and change the food - the results are different. The experiments performed in field conditions aimed at evaluation of changes in the number of harmful insects in the cereals treated with biopreparations have shown that the adult individuals of cereal leaf beetle and aphids tend to avoid the plants treated with different agents, like EM, $\mathrm{UG}_{\max }$, Asahi, Kelpak [10, 11].

In integrated pest control, the application of biopreparations, which have not been sufficiently investigated yet, may be very important. The present study does not provide information on the potential of their application in practice. However, under plot conditions significant differences have been observed in the abundance of pests on the cereal crops treated with those preparations, as compared with the control ones.

\section{REFERENCES}

1. Atanassova, M., Georgieva, S., Ivancheva, K. (2011) Total phenolic and total flavonoid contents, antioxidant capacity and biological contaminants in medicinal herbs. J. Univ. Chem. Technol. Metallurgy 46, 81-88.

2. Balcerek, M., Rąk, I., Majtkowska, G., Majtkowski, W. (2009) Antioxidant activity and total phenolic compounds in extracts of selected grasses (Poaceae). Herba Polonica 55, 214-221.

3. Cipollini, D., Stevenson, R., Enright, S., Eyles, A., Bonello, P. (2008) Phenolic metabolites in leaves of the invasive shrub, Lonicera maackii, and their potential phytotoxic and anti-herbivore effects. J. Chem. Ecol. 34, 144-152.

4. Clement, S. L., Hu, J., Stewart, A. V., Wang, B., Elberson, L. R. (2011) Detrimental and neutral effects of a wild grass-fungal endophyte symbiotum on insect preference and performance. J. Insect Sci. 11, $1-13$.

5. Cole, R. A. (1984) Phenolic acids associated with the resistance of lettuce cultivars to the lettuce root aphid. Ann. Appl. Biol. 105, 129-145.

6. Eleftherianos, I., Vamvatsikos, P., Ward, D., Gravanis, F. (2006) Changes in the levels of plant total phenols and free amino acids induced by two cereal aphids and effects on aphid fecundity. J. Appl. Entomol. 130, 15-19.

7. Ferry, N., Edwards, M. G., Gatehouse, J. A., Gatehouse, A. M. R. (2004) Plant-insect interactions: molecular approaches to insect resistance. Curr. Opin. Biotech. 15, 155-161.

8. Kotwica, K. (2009) Possibilities of alleviating negative effects of cereal growing after each other. Wyd. Uczel. UTP w Bydgoszczy, Rozprawy 129, 1-101. (In Polish) 
9. Kotwica, K., Jaskulska, I., Jaskulski, D., Gałęzewski, L., Walczak, D. (2011) Effect of nitrogen fertilisation and the method of soil fertilisation on winter wheat yielding depending on the previous crop. Fragm. Agron. 28, 53-63.

10. Lamparski, R., Kotwica, K., Jaskulski, D., Piekarczyk, M., Wawrzyniak, M. (2013) Influence of biopreparations in winter wheat on numbers of phytophagous insects. Fragm. Agron. 30, 108-114.

11. Lamparski, R., Szczepanek, M. (2013) Effect of bioregulator Kelpak application in spring wheat on the occurrence of phytophagous insects. Prog. Plant Prot. 53, 47-51.

12. Leszczyński, B. (1996) Practical course of chemical insects-plants interactions with aphids (Aphidoidea) as an example. Wyd. Uczel. WSRP $w$ Siedlcach, 1-390. (In Polish)

13. Leszczyński, B. (2010) Selected aspects of biochemistry and toxicology of the environment. Wyd. Akademii Podlaskiej, 1-173. (In Polish)

14. Maffei, M. E., Mithöfer, A., Boland, W. (2007) Before gene expression: early events in plant-insect interaction. Trends Plant Sci. 12, 310-316.

15. Mallikarjuna, N., Kranthi, K. R., Jadhav, D. R., Kranthi, S., Chandra, S. (2004) Influence of foliar chemical compounds on the development of Spodoptera litura (Fab.) in interspecific derivatives of groundnut. J. Appl. Entomol. 128, 321-328.

16. Michalski, T., Horoszkiewicz-Janka, J., Bartos, M. (2005) The effect of biopreparation Asahi SL on healthiness and yielding of barley and spring wheat. Prog. Plant Prot. 45, 910-913.

17. Modnicki, D., Balcerek, M. (2009) Estimation of total polyphenols contents in Ocimum basilicum L. Origanum vulgare L. and Thymus vulgaris L. commercial samples. Herba Polonica 55, 35-42.

18. Parylak, D. (2007) Soil environmental changes under the influence of simplifield tillage in continuous cropping of winter wheat. Fragm. Agron. 1, 213-220.

19. Pharmacopoeia Polonica IX (2011) Wyd. Polskie Towarzystwo Farmakologiczne, Warszawa, 1-1176. (In Polish)

20. Sandström, J., Telang, A., Moran, N. A. (2000) Nutritional enhancement of host plants by aphids - a comparison of three aphid species on grasses. J. Insect Physiol. 46, 33-40.

21. Sempruch, C. (2012) Interactions between aphids and plants during early steps of the host selection. Kosmos 61, 573-586.

22. Sempruch, C., Wójcicka, A., Leszczyński, B. (2009) Differences in feeding behaviour of grain aphid and bird cherry-oat aphid on winter triticale. Prog. Plant Prot. 49, 138-141.

23. Stotz, H. U., Kroymann, J., Mitchell-Olds, T. (1999) Plant-insect interactions. Curr. Opin. Plant Biol. 2, 268-272.

24. Tomczyk, A., Rudzińska, D. (2011) Influence of selected biostimulators on harmfulness of twospotted spider mite (Tetranychus urticae Koch) for glasshouse cucumber. Prog. Plant Prot. 51, 508512.

25. Wójcicka, A. (2008) Changes in content of Triticale phenolics induced by cereal aphids. Zesz. Probl. Post. Nauk Roln. 524, 447-454.

26. Wójcicka, A. (2010) Cereal phenolic compounds as biopesticides of cereal aphids. Pol. J. Environ. Stud. 19, 1337-1343.

27. Wójcicka, A., Leszczyński, B., Sempruch, C., Warzecha, R. (2007) Changes the level of cereal total phenols and $o$-dihydroxyphenols induced by aphids. Acta Physiol. Plant. 29 (Suppl. 1), 129. 